\title{
Morphea in Middle Anatolia, Turkey: a 5-year single-center experience
}

\author{
Isil Bulur, Hilal Kaya Erdoğan, Tekden Karapınar, Zeynep Nurhan Saracoglu
}

Department of Dermatology and Venereology, Faculty of Medicine, Eskisehir Osmangazi University, Eskisehir, Turkey

Adv Dermatol Allergol 2017; XXXIV (4): 334-338

DOI: https://doi.org/10.5114/ada.2017.69313

\begin{abstract}
Introduction: Morphea, also referred to as localized scleroderma, is a rare fibrosing skin disorder of undetermined cause.

Aim: We report our single-center experience with morphea.

Material and methods: The study included 53 patients who were diagnosed with morphea by histopathology in our department between 2010 and 2015. Study data were collected retrospectively from the records of morphea patients.

Results: The study included 53 patients (38 women, 15 men), and median age at onset was 39.0 (range: 8-85) years. Thirty (56.6\%) patients had circumscribed morphea, 15 (28.3\%) had generalized morphea, and 7 (13.2\%) had linear morphea. One patient had mixed variant morphea (generalized, pansclerotic and linear morphea). ANA positivity was detected in 12 (22.6\%) patients, but analysis for an association between the presence of ANA and morphea types, patients' characteristics did not reveal any significant associations. We did not observe any extracutaneous manifestations in patients during follow-up period. There were 2 of 53 patients who had concomitant autoimmune disorder including vitiligo and spondyloarthritis. Thirty (56.6\%) patients received only topical treatment. The patients with clinical improvement who were treated with systemic therapy received methotrexate (26.4\%), colchicine (9.4\%), mycophenolate mofetil (5.7\%) and prednisolone (1.9\%).

Conclusions: Our results related to the demographic data of the patients and morphea types were consistent with the literature. On the other hand we observed that methotrexate was mostly used as an effective treatment option for generalized morphea.
\end{abstract}

Key words: morphea, localized scleroderma, antinuclear antibody, treatment.

\section{Introduction}

Morphea (localized scleroderma, scleroderma localisata, scleroderma circumscripta) is a chronic inflammatory disease characterized by abnormal cellular immunity, collagen synthesis and microcirculation [1]. The incidence of the disease has been reported as 0.2 to 2.7 per 100000 persons in epidemiologic studies [2]. The characteristic lesion of morphea is the limited sclerotic plaque with an ivory-colored center. The clinical course depends on the morphea type and spread of the disease. According to Laxer and Zulian, the disease has five variants consisting of circumscribed, linear, generalized, pansclerotic and mixed ones [3].

\section{Aim}

In this study, we present the demographic, clinical and therapeutic characteristics of 53 patients with morphea, which were clinically and histopathologically diagnosed and followed-up at our clinic during a 5-year period.

\section{Material and methods}

Patients who attended our Dermatology Department and were histopathologically confirmed with morphea between 2010 and 2015 were included in this study. The data of the patients were retrospectively evaluated from the patients' charts. Morphea cases were divided into five groups as circumscribed, linear, generalized, pansclerotic and mixed variant morphea, according to the classification of Laxer and Zulian [3].

Clinical improvement was defined as the absence of the following criteria suggested by Careta and Romiti for disease activity [4]:

Address for correspondence: Isil Bulur MD, Department of Dermatology and Venereology, Faculty of Medicine, Eskişehir Osmangazi University, Eskisehir, Turkey, phone: +90 22223929 79-3558, e-mail: isilbulur@yahoo.com

Received: 9.03.2016, accepted: 3.06.2016. 
- Appearance of new lesions in the last 3 months (documented by the physician);

- Expansion of the pre-existing lesion in the last 3 months (documented by the physician);

- Moderate or severe erythema or skin lesions with erythematous borders;

- Violaceous lesion or lesion border;

- Increased induration of the lesion border;

- Worsening of hair loss on the scalp, eyebrows or eyelashes (documented by the physician).

Systemic treatment was given in circumscribed and linear morphea which were unresponsive to topical treatment and generalized, pansclerotic and mixed morphea.

\section{Statistical analysis}

Continuous data were presented as mean \pm standard deviation. Categorical data were given as percentages (\%). The Shapiro-Wilk test was used to evaluate data with a normal distribution. The Mann-Whitney $U$ test was used to compare two groups that were not consistent with the normal distribution. Pearson Exact $\chi^{2}$ and Fisher Exact $\chi^{2}$ analyses were used in the analysis of the cross tables. The IBM SPSS Statistics 21.0 program was used for the analysis. A p-value $<0.05$ was accepted as the criterion for statistical significance.

\section{Results}

The study included 53 patients (38 women, 15 men) with a median age at onset of 39.0 (range: 8-85) years.

Table 1. Characteristics of 53 patients with morphea

\begin{tabular}{lc}
\hline Parameter & Results \\
\hline Age [year] & $39(8-85)$ \\
\hline Gender: & $38(71.7)$ \\
\hline Women & $15(28.3)$ \\
\hline Men & $7(13.2)$ \\
\hline Circumscribed morphea & $15(28.3)$ \\
\hline Linear morphea & $1(1.9)$ \\
\hline Generalized morphea & $30(56.6)$ \\
\hline Mixed variant morphea & $15.7)$ \\
\hline Body segment involved: & $13(81.1)$ \\
\hline Head & $23(43.4)$ \\
\hline Trunk & $14(26.4)$ \\
\hline Upper limbs & $12(22.6)$ \\
\hline Lower limbs & $1.9)$ \\
\hline Antinuclear antibodies & \\
\hline Systemic autoimmune disease: & \\
\hline Vitiligo & \\
\hline Vitiligo + spondyloarthritis & \\
\hline
\end{tabular}

Results are given as median value (range) or number (\%).
Thirty (56.6\%) patients had circumscribed morphea, 7 (13.2\%) had linear morphea and 15 (28.3\%) had generalized morphea. One patient had mixed variant morphea (consisting of generalized, pansclerotic and linear morphea). The most common locations were the trunk (81.1\%) and upper limbs (43.4\%). Antinuclear antibody (ANA) positivity was detected in $12(22.6 \%)$ patients with $6(11.3 \%)$ patients + positive, $4(7.5 \%)++$ positive, and $2(3.8 \%)+++$ positive (Figure 1$)$. A concomitant autoimmune disorder including vitiligo and vitiligo + spondyloarthritis was present in 2 (3.8\%) of 53 patients. We did not observe any extracutaneous manifestations during follow-up. The characteristics of the patients are presented in Table 1.

The patients were divided into two groups as the pediatric group under the age of 18 years and the adult group aged 18 and older, with 9 and 44 patients, respectively. No difference was found between the groups in terms of gender and ANA positivity $(p=0.252, p=1.00)$ (Table 2). Circumscribed morphea was the most common subtype in the adult group (63.6\%) and linear (33.3\%) and generalized morphea (33.3\%) were the two most common subtypes in the pediatric group (Table 2).

The patients were divided into two groups according to ANA positivity. The mean age was $38.6 \pm 19.8$ in ANAnegative and $46.8 \pm 23$ in ANA-positive patients with no statistically significant difference $(p=0.226)$. There was also no difference between these two groups for gender or disease type ( $p=1.00, p=0.409)$ (Table 3$)$.

Thirty (56.6\%) patients received only topical treatments including topical corticosteroids, topical calcineurin inhibitors. The patients who showed clinical improvement on systemic therapy were treated with methotrexate (26.4\%), colchicine (9.4\%), mycophenolate

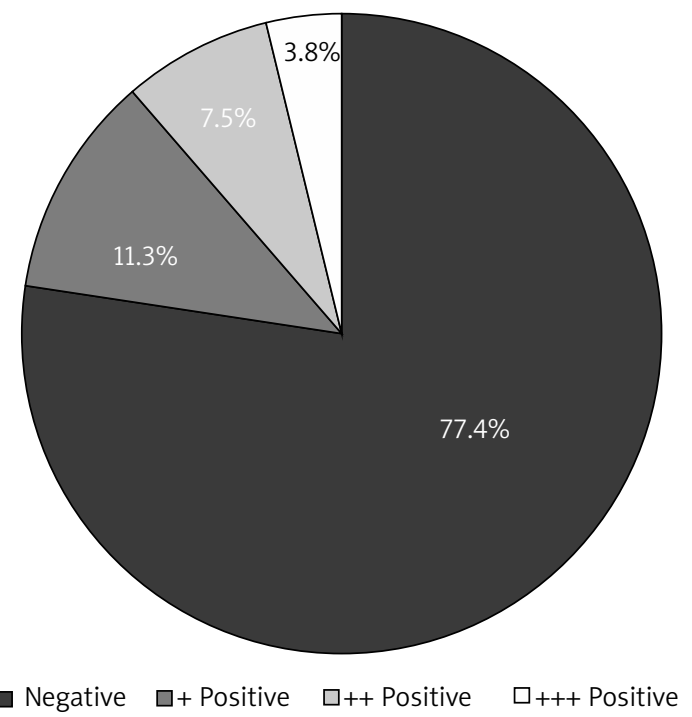

Figure 1. The distribution of patients according to ANA positivity 
Table 2. Patient characteristics in pediatric and adult groups

\begin{tabular}{|c|c|c|c|}
\hline Parameter & $\begin{array}{c}\text { Pediatric cases }(<18) \\
n=9\end{array}$ & $\begin{array}{c}\text { Adult cases }(\geq 18) \\
n=44\end{array}$ & $P$-value \\
\hline Gender: & & & $0.252^{\star *}$ \\
\hline Female & $5(55.6 \%)$ & $33(75.0 \%)$ & \\
\hline Male & $4(44.4 \%)$ & $11(25.0 \%)$ & \\
\hline \multicolumn{4}{|l|}{ Classification of lesion: } \\
\hline Circumscribed morphea & $2(22.2 \%)$ & $28(63.6 \%)$ & $0.042^{*}$ \\
\hline Linear morphea & $3(33.3 \%)$ & $4(9.1 \%)$ & \\
\hline Generalized morphea & $3(33.3 \%)$ & $12(27.3 \%)$ & \\
\hline Mixed variant morphea & $1(11.1 \%)$ & & \\
\hline ANA: & & & $1.00^{\star *}$ \\
\hline Negative & $6(75.0 \%)$ & 35 (79.5\%) & \\
\hline Positive & 2 (25.0\%) & 9 (20.5\%) & \\
\hline
\end{tabular}

*Pearson exact $\chi^{2}$ test, ${ }^{* *}$ Fishers exact $\chi^{2}$ test.

Table 3. Patient characteristics according to ANA positivity

\begin{tabular}{|c|c|c|c|}
\hline Parameter & $\begin{array}{c}\text { ANA negative } \\
n=41\end{array}$ & $\begin{array}{c}\text { ANA positive } \\
n=12\end{array}$ & $P$-value \\
\hline Age [year] & $36.58 \pm 19.78$ & $46.8 \pm 22.3$ & $0.226^{*}$ \\
\hline \multicolumn{4}{|l|}{ Gender: } \\
\hline Female & $29(70.7 \%)$ & $9(75.0 \%)$ & $1.00^{\star *}$ \\
\hline Male & $12(29.3 \%)$ & $3(25.0 \%)$ & \\
\hline \multicolumn{4}{|l|}{ Classification of lesion: } \\
\hline Circumscribed morphea & $23(56.1 \%)$ & $7(58.3 \%)$ & $0.409^{* \star *}$ \\
\hline Linear morphea & $6(14.6 \%)$ & $1(8.3 \%)$ & \\
\hline Generalized morphea & $12(29.3 \%)$ & $3(33.3 \%)$ & \\
\hline Mixed variant morphea & & $1(8.3 \%)$ & \\
\hline
\end{tabular}

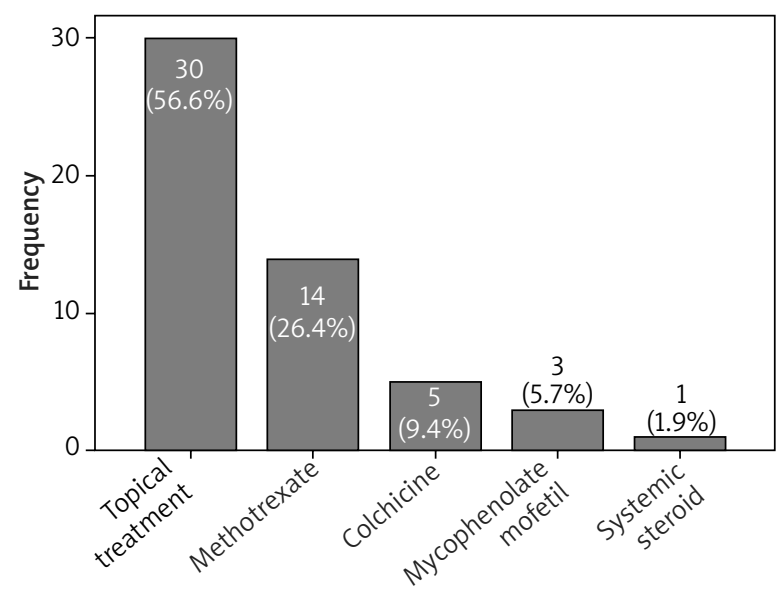

Figure 2. The distribution of patients according to treatments mofetil (5.7\%) and prednisolone (1.9\%). The distribution of the patients according to treatment is presented in Figure 2.

\section{Discussion}

Morphea is a rare skin disease characterized by skin fibrosis, and there is a limited number of case series in the literature. A total of 53 patients who were histopathologically confirmed to have morphea in a 5 -year period were included in our study. Several retrospective reviews reported that females are affected $2-3$ times more often than males, and the mean age of presentation is in mid40 s [2, 3]. Consistent with the studies in the literature, we observed a female predominance and the median age was 39 (8-85) years in our study. Circumscribed morphea 
(plaque morphea) is reported to be the most common morphea type in adulthood [5, 6]. Circumscribed morphea was also the most common morphea type in our study. The generalized morphea rate has been reported as $13-24 \%$ in other studies [7, 8], and was $28.3 \%$ in our study. One of our cases, a 16-year-old female, had mixed variant morphea consisting of generalized, pansclerotic and linear morphea. Evaluation of morphea subtypes separately in adult and pediatric cases revealed the most common subtype to be circumscribed morphea in adults, and linear and generalized types in pediatric cases in this study.

Extracutaneous involvement such as musculoskeletal (arthritis, arthralgia), neurological, ocular problems, respiratory (coughing, dyspnea, restrictive lung disease), gastrointestinal tract (gastroesophageal reflux, esophagitis), cardiac, kidney disorders and Raynaud phenomenon can be seen in morphea patients [9]. Systemic involvement has been reported to occur in $24-46 \%$ of generalized and linear morphea cases. However, extracutaneous involvement was not seen in any of our patients.

An increased incidence of autoimmune diseases and autoantibodies has been reported in morphea patients $[10,11]$. Leitenberger et al. reported autoimmune disorders to be seen equally commonly in adult and pediatric patients in their study where 245 morphea patients were evaluated [8]. Generalized morphea is defined as the most common morphea accompanying autoimmune disease in both children and adults [8]. In our study, an 11-year-old child with generalized morphea had vitiligo, and a 43-year-old patient with circumscribed morphea had vitiligo and spondyloarthritis.

The incidence of ANA positivity in morphea cases has been reported as 5.9-73\% [8]. ANA positivity has been reported to be more common in adults (45-53\%) than in children (26-53\%) with morphea [8, 9]. Besides, the ANA positivity rate has been reported to be higher in generalized morphea [5, 8]. We did not find a statistically significant difference in terms of age, gender and morphea clinical type between the ANA-positive and -negative patients in our study. There was also no statistically significant difference between the pediatric and adult age groups in terms of ANA positivity.

The treatment in morphea is determined according to the severity and extent of the disease, the movement limitation and deformity risk [12]. Localized plaque lesions can be treated with topical and intralesional steroids, calcipotriol ointment, imiquimod or phototherapy. The agents commonly used in systemic treatment are systemic steroids, hydroxychloroquine, sulfasalazine, D-penicillamine, methotrexate, cyclosporine, photospheres, interferon, and phototherapy [3, 13]. Although colchicine treatment is not present in treatment algorithms, it has been shown to be effective in controlling the disease in various studies. Parlak et al. reported that new lesions were prevented in $91.3 \%$ of 23 morphea pa- tients started on colchicine treatment and that colchicine is an effective and reliable treatment option for morphea [14]. A clinical response was obtained with colchicine treatment in 5 (9.4\%) of our patients. Methotrexate and mycophenolate mofetil (MMF) has been shown to be a good option in resistant cases in various studies [13, 15, 16]. However, the effectiveness of methotrexate and MMF should be supported with randomized controlled studies. We obtained clinical response with methotrexate in 14 patients resistant to topical and systemic steroids and colchicine treatment, and with MMF in 2 generalized morphea cases and 1 mixed type morphea case also resistant to methotrexate without any adverse effect.

The most important limitation of our study was its retrospective nature. On the other hand, it is valuable, because there is only one study reporting the case series including the adult age group from Turkey so far [14].

\section{Conclusions}

In our study, the most commonly observed morphea type in adults was the circumscribed type while the linear and generalized types were the most common types in the pediatric group. The morphea subtypes in our pediatric cases was different from the literature. The reason may be the low number of patients in our study and the fact that our hospital is a tertiary-care center, so only the patients who should be given systemic treatment are referred to our clinic. No difference in terms of age, gender and morphea subtype was found between the ANA-positive and -negative groups. According to our data, methotrexate is the most common and effective treatment agent while MMF can also be effective and reliable in methotrexate-resistant cases.

\section{Conflict of interest}

The authors declare no conflict of interest.

\section{References}

1. Valančienė $G$, Jasaitienè $D$, Valiukevičienė $S$. Pathogenesis and treatment modalities of localized scleroderma. Medicina (Kaunas) 2010; 46: 649-56.

2. Fett N, Werth VP. Update on morphea: part I. Epidemiology, clinical presentation, and pathogenesis. I Am Acad Dermatol 2011; 64: 217-28.

3. Laxer RM, Zulian F. Localized scleroderma. Curr Opin Rheumatol 2006; 18: 606-13.

4. Careta MF, Romiti R. Localized scleroderma: clinical spectrum and therapeutic update. An Bras Dermatol 2015; 90 : 62-73.

5. Marzano AV, Menni S, Borghi A, et al. Localized scleroderma in adults and children. Clinical and laboratory investigations on 239 cases. Eur J Dermatol 2003; 13: 171-6.

6. Peterson LS, Nelson AM, Su WP. Classification of morphea (localized scleroderma). Mayo Clin Proc 1995; 70: 1068-76. 
7. Peterson LS, Nelson AM, Su WP, et al. The epidemiology of morphea (localized scleroderma) in Olmsted County 19601993. J Rheumatol 1997; 24: 73-80.

8. Leitenberger JJ, Cayce RL, Haley RW, et al. Distinct autoimmune syndromes in morphea: a review of 245 adult and pediatric cases. Arch Dermatol 2009; 145: 545-50.

9. Gorkiewicz-Petkow A, Kalinska-Bienias A. Systemic involvement in localized scleroderma/morphea. Clin Dermatol 2015; 33: 556-62.

10. Zulian F, Vallongo C, Woo P, et al. Localized scleroderma in childhood is not just a skin disease. Arthritis Rheum 2005. 52: 2873-81.

11. Yorulmaz A, Kilic S, Artuz F, Kahraman E. Concomitant appearance of morphea and vitiligo in a patient with autoimmune thyroiditis. Adv Dermatol Allergol 2016; 33: 314-6.

12. Bielsa Marsol I. Update on the classification and treatment of localized scleroderma. Actas Dermosifiliogr 2013; 104 654-66.

13. Fett N, Werth VP. Update on morphea: part II. Outcome measures and treatment. J Am Acad Dermatol 2011; 64: 231-42.

14. Parlak N, Akay BN, Şanlı HE, et al. The clinical features, laboratory findings, treatment and follow-up results of patients with morphea. Turkderm 2013; 47: 209-13.

15. Martini G, Ramanan AV, Falcini F, et al. Successful treatment of severe or methotrexate resistant juvenile localized scleroderma with mycophenolate mofetil. Rheumatology (Oxford) 2009; 48: 1410-3.

16. Mertens JS, Marsman D, van de Kerkhof PC, et al. Use of mycophenolate mofetil in patients with severe localized scleroderma resistant or intolerant to methotrexate. Acta Derm Venereol 2016; 96: 510-3. 